\title{
Intersystem Crossings Drive Atmospheric Gas-Phase Dimer Formation
}

\author{
Valiev, Rashid
}

2019-08-01

Valiev , R , Hasan , G , Salo , V-T , Kubecka , J \& Kurten , T 2019 , ' Intersystem Crossings

Drive Atmospheric Gas-Phase Dimer Formation ' , Journal of Physical Chemistry A, vol. 123 , no. 30 , pp. 6596-6604 . https://doi.org/10.1021/acs.jpca.9b02559

http://hdl.handle.net/10138/317518

https://doi.org/10.1021/acs.jpca.9b02559

acceptedVersion

Downloaded from Helda, University of Helsinki institutional repository.

This is an electronic reprint of the original article.

This reprint may differ from the original in pagination and typographic detail.

Please cite the original version. 


\title{
Intersystem Crossings Drive Atmospheric Gas-
}

\section{Phase Dimer Formation}

Rashid R. Valiev ${ }^{1,2}$, Galib Hasan ${ }^{1,3}$, Vili-Taneli Salo ${ }^{1,3}$, Jakub Kubečka ${ }^{3}$, Theo Kurten ${ }^{1,3}$

1. University of Helsinki, Department of Chemistry, P.O. Box 55 (A.I. Virtanens plats 1), FIN-00014 University of Helsinki, Finland

2. Tomsk State University, 36, Lenin Avenue, 634050 Tomsk, Russia

3. University of Helsinki, Institute for Atmospheric and Earth System Research, Helsinki 00014, Finland

\section{AUTHOR INFORMATION}

\section{Corresponding Author}

*E-mail:valievrashid@gmail.com, theo.kurten@helsinki.fi

\begin{abstract}
High-molecular weight "ROOR"" dimers, likely formed in the gas phase through self- and cross-reactions of complex peroxy radicals $\left(\mathrm{RO}_{2}\right)$, have been suggested to play a key role in forming ultrafine aerosol particles in the atmosphere. However, the molecular-level reaction mechanism producing these dimers remains unknown. Using multireference quantum chemical methods, we explore one potentially competitive pathway for ROOR' production, involving the initial formation of triplet alkoxy radical (RO) pairs, followed by extremely rapid intersystem crossings (ISC) to the singlet surface, permitting subsequent recombination to ROO $\mathrm{R}^{\prime}$. Using $\mathrm{CH}_{3} \mathrm{OO}+\mathrm{CH}_{3} \mathrm{OO}$ as a model system, we show that the initial steps of this reaction mechanism are likely to be very fast, as the transition states for both the formation and the
\end{abstract}


decomposition of the $\mathrm{CH}_{3} \mathrm{O}_{4} \mathrm{CH}_{3}$ tetroxide intermediate are far below the reactants in energy. Next, we compute ISC rates for seven different atmospherically relevant ${ }^{3}\left(\mathrm{RO} \ldots \mathrm{R}^{\prime} \mathrm{O}\right)$ complexes. The ISC rates vary significantly depending on the conformation of the complex, and also exhibit strong stereoselectivity. Furthermore, the fastest ISC process is usually not between the lowest-energy triplet and singlet states, but between the triplet ground state and an exited singlet state. For each studied (RO...R'O) system, at least one low-energy conformer with an ISC rate above $10^{8} \mathrm{~s}^{-1}$ can be found. This demonstrates that gas-phase dimer formation in the atmosphere very likely involves ISCs originating in relativistic quantum mechanics.

\section{TOC GRAPHICS}

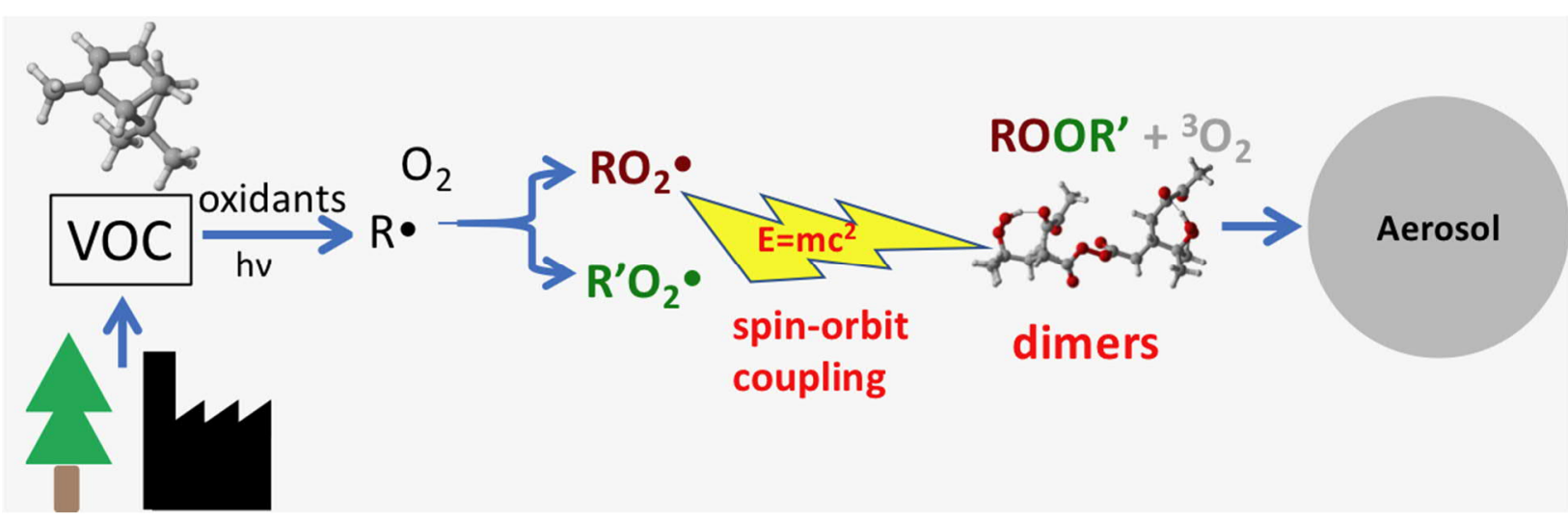

KEYWORDS. alkoxy radicals, atmospheric chemistry, dimer formation, peroxy radicals, selfreaction, cross-reaction, intersystem crossing, internal conversion, XMC-QDPT2

\section{INTRODUCTION}

Fine and ultrafine aerosol particles (with diameters less than $1 \mu \mathrm{m}$ and $0.1 \mu \mathrm{m}$, respectively) constitute a serious health risk as they can penetrate deeply into the lung of humans, as well as other animals. Particulate air pollution is responsible for at least around three million premature deaths per year globally. ${ }^{1,2}$ Aerosol particles also affect the climate by influencing the distribution and radiative properties of Earth's clouds. This is currently the least understood 
component of global radiative forcing. ${ }^{3}$ The majority of submicron particles, responsible for most air pollution-related mortality, are secondary - they are formed in the air from condensable, mostly organic, vapors. Despite the health and climate impact of secondary organic aerosol (SOA), the gas-phase processes involved in converting volatile organic emissions into the leastvolatile fraction of SOA, capable of condensing onto nanometer-scale particles, remain incompletely understood. Numerous recent laboratory and field studies ${ }^{4-8}$ indicate that the lowest-volatility SOA precursors consist of covalently bonded accretion products (typically referred to as "dimer" molecules) which are formed in the gas phase.

Dimer, and more generally oligomer, formation has been recognized as an important process in SOA formation for more than a decade. ${ }^{9,10}$ However, most proposed oligomerization processes are unable to explain gas-phase dimer formation: for example esterification and other similar condensation processes are restricted to the liquid phase, while reactions involving for example stabilized Criegee Intermediates ( $\mathrm{sCI}$ ) generally have too low yields due to the very low atmospheric concentrations of sCIs. Peroxy radical $\left(\mathrm{RO}_{2}\right)$ recombination, $\mathrm{RO}_{2}+\mathrm{R}^{\prime} \mathrm{O}_{2} \rightarrow$ ROOR' $+\mathrm{O}_{2}$, provides a dimerization mechanism that phenomenologically fits the observational gas-phase data well. ${ }^{11}$ However, experiments ${ }^{12,13}$, and computational studies ${ }^{14,15}$ on simple peroxyradicals following the established 60 -year old Russell mechanism for $\mathrm{RO}_{2}$ self-reactions, ${ }^{16}$ suggest that this channel is negligible compared to the competing channels forming $\mathrm{RO}+\mathrm{R}^{\prime} \mathrm{O}+$ $\mathrm{O}_{2}$ or $\mathrm{R}_{-\mathrm{H}}=\mathrm{O}+\mathrm{R}^{\prime} \mathrm{OH}+\mathrm{O}_{2}$. The Russell mechanism postulates that $\mathrm{RO}_{2}+\mathrm{R}^{\prime} \mathrm{O}_{2}$ reactions first lead to a metastable $\mathrm{RO}_{4} \mathrm{R}$ ' tetroxide intermediate, which then undergoes different types of rearrangements to yield the three product channels: $\mathrm{RO}+\mathrm{R}^{\prime} \mathrm{O}+\mathrm{O}_{2}, \mathrm{R}_{-\mathrm{H}}=\mathrm{O}+\mathrm{R}^{\prime} \mathrm{OH}+\mathrm{O}_{2}$ or ROOR' $+\mathrm{O}_{2}$, with the latter believed until recently to only occur in the condensed phase. This belief was conclusively demonstrated to be wrong by Berndt et al., who reported efficient 
formation of ROOR' species from the cross- and self-reactions of multiple $\mathrm{RO}_{2}$ species including $\mathrm{CH}_{3} \mathrm{C}(\mathrm{O}) \mathrm{CH}_{2} \mathrm{O}_{2}$ (from tetramethylethylene ozonolysis), $\mathrm{HO}-\mathrm{C}_{4} \mathrm{H}_{8} \mathrm{O}_{2}$ (from $\mathrm{OH}-\mathrm{oxidation}$ of 1butene), $\mathrm{HO}-\mathrm{C}_{5} \mathrm{H}_{8} \mathrm{O}_{2}$ (from $\mathrm{OH}$-oxidation of isoprene), as well as multiple generations of larger $\mathrm{RO}_{2}$ originating from the oxidation of 1,3,5-trimethylbenzene. ${ }^{11}$ The self- and cross-reaction rates for ROOR' formation from these species were on the order of $10^{-13} \ldots 10^{-10} \mathrm{~cm}^{3}$ molecule ${ }^{-1}$ $\mathrm{s}^{-1}$, with the rates increasing with the size and complexity of the $\mathrm{RO}_{2}$. These fast rates are incompatible with computational studies ${ }^{14,15}$ finding high barriers for the "Russell" - type rearrangement of $\mathrm{RO}_{4} \mathrm{R}^{\prime}$ to $\mathrm{ROOR}$ ' $+\mathrm{O}_{2}$. A recent theoretical study by Lee et al. ${ }^{17}$, building upon an older study by Ghigo et al. ${ }^{18}$, provides a partial explanation for this discrepancy. According to the mechanism proposed by Ghigo et al. and Lee et al. (see Figure 1 for a schematic summary), all $\mathrm{RO}_{2}+\mathrm{R}^{\prime} \mathrm{O}_{2}$ channels proceed through the same singlet (all electrons paired) $\mathrm{RO}_{4} \mathrm{R}^{\prime}$ tetroxide intermediate, which instead of Russell-type rearrangements undergoes two bond cleavages to form a singlet $\mathrm{RO} \ldots \mathrm{O}_{2} \ldots . . \mathrm{R}$ O complex, where $\mathrm{O}_{2}$ is in its triplet ground state (two unpaired electrons with the same spin). To preserve the overall singlet spin multiplicity, the two RO radicals must also be coupled as a triplet, i.e. the two radical electrons must have the same spin. ROOR' formation is thus prevented not by a conventional energy barrier, but by the Pauli principle, which forbids two radicals with the same spin from recombining. ROOR' formation from the ${ }^{3}(\mathrm{RO} \ldots \mathrm{RO})$ triplet pair requires an intersystem crossing (ISC, "spin-flip"), an effect originating in relativistic ("Dirac") quantum mechanics, through the coupling of an electron's spin with its motion inside the potential induced by the atomic nuclei and other electrons. Changes of spin multiplicity are forbidden in nonrelativistic ("Schrödinger") quantum mechanics, explaining why previous studies restricted to a single potential energy surface have not found competitive channels for ROOR'. Unfortunately, the Lee 
et al. study did not provide any estimates for ISC rates, and the rate-limiting barriers given in their data are also far too high compared to experimental overall $\mathrm{RO}_{2}+\mathrm{R}^{\prime} \mathrm{O}_{2}$ rates. Thus, their data predict far too slow rates not only for ROOR' formation, but for any of the three $\mathrm{RO}_{2}+$ $\mathrm{R}^{\prime} \mathrm{O}_{2}$ reaction channels. However, the barrier heights reported by Lee et al may contain large uncertainties due to the limited accuracy of single-reference methods (even the "gold standard" coupled cluster method $\operatorname{CCSD}(\mathrm{T})$ ) in treating systems with four unpaired electrons coupled first as two triplets, which then couple to an overall singlet. ${ }^{19}$

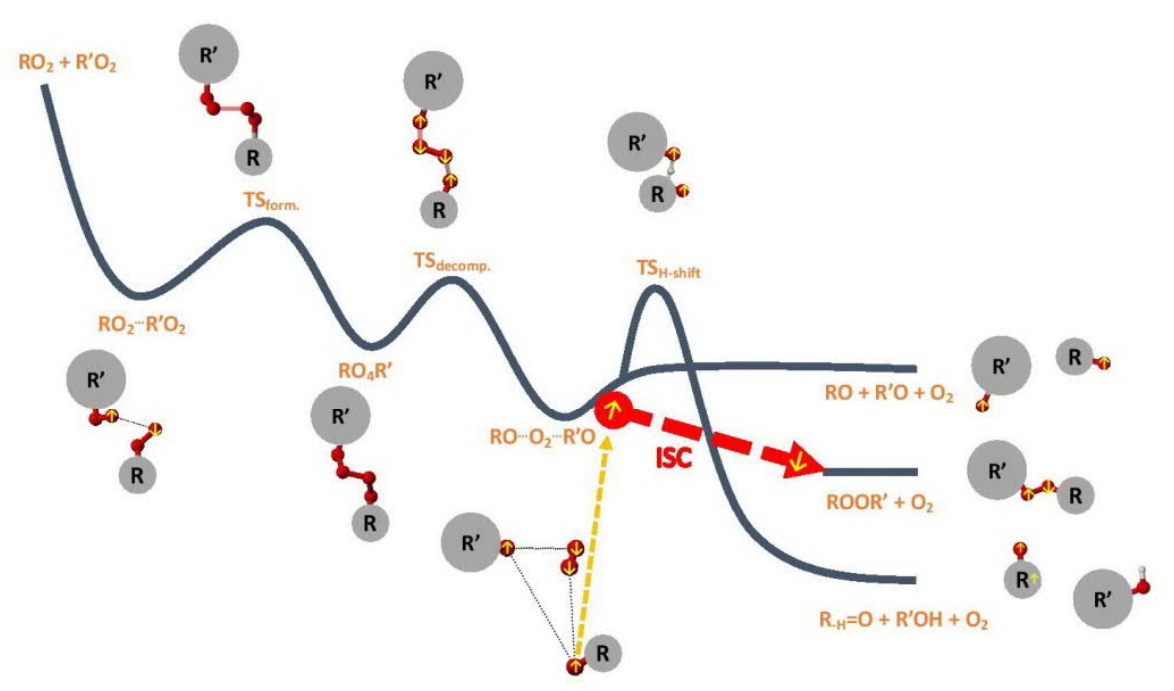

Fig. 1. Schematic potential energy surface (not to scale) illustrating the general mechanism for ROOR dimer formation, based on Ghigo et $\mathrm{al}^{18}$, Lee et $\mathrm{al}^{17}$ and this study. The two RO2 first collide to form a complex, $\mathrm{RO}_{2} \ldots \mathrm{R}^{\prime} \mathrm{O}_{2}$, which then reacts (via a transition state labelled TSform.) to form the $\mathrm{RO}_{4} \mathrm{R}^{\prime}$ tetroxide. This decomposes via another transition state (labelled TSdecomp.) to form a $\mathrm{RO} \ldots \mathrm{O}_{2} \ldots \mathrm{R}$ 'O complex with four unpaired electrons. The complex can either dissociate to $\mathrm{RO}+\mathrm{R}^{\prime} \mathrm{O}+\mathrm{O}_{2}$, cross a barrier (labelled TSH-shift) to form $\mathrm{R}-\mathrm{H}=\mathrm{O}+\mathrm{R}$ ' OH $+\mathrm{O}_{2}$, or undergo an intersystem crossing (ISC, illustrated by a red arrow) followed by rapid recombination to give ROOR' $+\mathrm{O}_{2}$. The four oxygen atoms are illustrated in as red spheres, and the unpaired electrons (as well as the corresponding electron pair in the ROOR' dimer) are indicated by yellow arrows. The hydrogen atom abstracted in TSH-shift is illustrated by a white sphere. Note that the Ghigo et al. study did not find TSform, while the Lee et al. study found two 
separate transition states for the $\mathrm{RO}_{4} \mathrm{R}^{\prime}$ decomposition. The mechanism depicted here corresponds to that found in this study.

In this study, we first apply multireference methods, including both static and dynamic correlation, to the $\mathrm{CH}_{3} \mathrm{OO}+\mathrm{CH}_{3} \mathrm{OO}$ reaction to assess whether the general mechanism presented by Lee et al. (and earlier by Ghigo et al.) can yield barrier heights in qualitative agreement with experimental overall $\mathrm{RO}_{2}+\mathrm{R}^{\prime} \mathrm{O}_{2}$ rates. We then evaluate ISC rates for a number of different ${ }^{3}\left(\mathrm{RO} \ldots \mathrm{R}^{\prime} \mathrm{O}\right)$ complexes, including those formed in the systems studied by Berndt et al. ${ }^{11}$

\section{ACTIVATION BARRIERS FOR $\mathrm{CH}_{3} \mathrm{O}_{4} \mathrm{CH}_{3}$ FORMATION AND DECOMPOSITION}

The transition states for the formation and decomposition of $\mathrm{CH}_{3} \mathrm{O}_{4} \mathrm{CH}_{3}$ must be treated with a multireference method also including dynamic correlation of electrons. See section S1 in the Supporting Information (SI) for an evaluation of the multireference character of the stationary points shown in Figure 1 for the $\mathrm{R}=\mathrm{CH}_{3}$ case. In this study, we use the extended quasidegenerate $2^{\text {nd }}$-order multireference perturbation theory $(\mathrm{XMC}-\mathrm{QDPT} 2)^{20}$, with the 6$311 \mathrm{G}++(\mathrm{d}, \mathrm{p})$ basis set, as implemented in the Firefly program ${ }^{21}$, for calculating the structures and energies of $\mathrm{CH}_{3} \mathrm{O}_{4} \mathrm{CH}_{3}$, and the transition states for its formation (from $\mathrm{CH}_{3} \mathrm{OO}+\mathrm{CH}_{3} \mathrm{OO}$ ) and decomposition (to $\mathrm{CH}_{3} \mathrm{O} \ldots \mathrm{O}_{2} \ldots \mathrm{CH}_{3} \mathrm{O}$ ). As the energies of the first singlet excited states are above $7000 \mathrm{~cm}^{-1}$ for all the four discussed stationary points (See section S4 of the SI), we consider only the ground singlet electronic state in this section. The XMC-QDPT2 method has previously been successfully applied to complex chemical systems of varying sizes, including radical systems. ${ }^{22-25}$ We chose an active space consisting of 10 electrons in 8 molecular orbitals (MOs) for searching for the singlet ground states of both transition states (TS) and minima, using 
the same orbitals for all four stationary points. The only previous multireference study on $\mathrm{RO}_{2}+$ $\mathrm{R}^{\prime} \mathrm{O}_{2}$ reactions, the complete active space self-consistent field (CASSCF) study of Ghigo et al., ${ }^{18}$ also suggests that the same 10,8 active space is sufficient for describing the decomposition of $\mathrm{CH}_{3} \mathrm{O}_{4} \mathrm{CH}_{3}$ (they did not find a transition state for its formation). The initial canonical orbitals were generated at the Hartree-Fock (HF) level of theory, and were added to the active space based on visual inspection. The active spaces of the $\mathrm{RO}_{2} \ldots \mathrm{R}^{\prime} \mathrm{O}_{2}$ complex (with $\mathrm{R}=\mathrm{CH}_{3}$ ) and the associated transition state leading to the $\mathrm{RO}_{4} \mathrm{R}^{\prime}$ tetroxide were built from 1) two MOs corresponding to combinations of the bonding $\sigma$-MOs of the O-O bonds of each of the two $\mathrm{RO}_{2}$ radicals, 2) two MOs corresponding to combinations of the antibonding $\sigma^{*}$-MOs of the same bonds, 3) two MOs corresponding to combinations of the lone pairs located on each radical, and 4) two MOs corresponding to $\pi$-bonding MOs of the O-O bonds of each radical. The active spaces of the $\mathrm{RO}_{4} \mathrm{R}^{\prime}$ tetroxide and the transition state for its decomposition were built from the same $\sigma$ - and $\sigma^{*}$-MOs as described above, plus 1) the bonding and antibonding $\sigma$ - and $\sigma^{*}$-MOs of the nascent $\mathrm{O}_{2}$ molecule (i.e. the central $\mathrm{O}-\mathrm{O}$ bond in the $\mathrm{RO}_{4} \mathrm{R}^{\prime}$ tetroxide), and 2) two MOs corresponding to combinations of the $\pi$-MOs of the nascent $\mathrm{O}_{2}$ molecule. See section $\mathrm{S} 2$ of the SI for systematic benchmarking of the effect of basis set size, active space, and method used to treat dynamic electron correlation. As shown in section S2, the effect of increasing basis set or active space size on the barrier heights relative to $\mathrm{CH}_{3} \mathrm{O}_{4} \mathrm{CH}_{3}$ are minor. Compared to the most accurate (and also expensive) method available, MRCISD, XMC-QDPT2 performs best out of three tested perturbation theory - based approaches, albeit still with error margins of several $\mathrm{kcal} / \mathrm{mol}$.

The potential energy surface for the $\mathrm{CH}_{3} \mathrm{OO}+\mathrm{CH}_{3} \mathrm{OO}$ reaction, computed at the $\mathrm{XMC}$ QDPT2 $(10,8) / 6-311++\mathrm{G}(\mathrm{d}, \mathrm{p})$ level, is illustrated in Figure 2, and the Cartesian coordinates for 
all studied stationary points (optimized at this level) are given in section S6 of the SI. In contrast to Lee et al., but in agreement with the CASSCF study of Ghigo et al., we find that the decomposition of $\mathrm{RO}_{4} \mathrm{R}^{\prime}$ to $\mathrm{RO} \ldots \mathrm{O}_{2} \ldots \mathrm{R}$ 'O occurs via a single transition state. The activation barrier for the formation of $\mathrm{RO}_{4} \mathrm{R}^{\prime}$ (the energy difference between the $\mathrm{RO}_{2} \ldots \mathrm{R}^{\prime} \mathrm{O}_{2}$ complex and the transition state leading to $\mathrm{RO}_{4} \mathrm{R}^{\prime}$ ) is $1.42 \mathrm{kcal} / \mathrm{mol}$, while the activation barrier for $\mathrm{RO}_{4} \mathrm{R}^{\prime}$

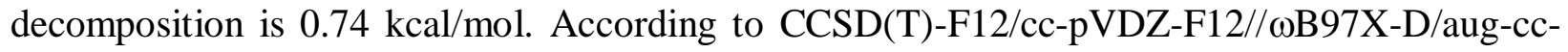
pVTZ calculations (see section S1 in the supplementary information for details), the tetroxide lies more than $15 \mathrm{kcal} / \mathrm{mol}$ below the free reactants in energy. Both transition states thus correspond to submerged barriers, and are unlikely to significantly hinder the reaction in atmospheric conditions. The formation and decomposition of $\mathrm{CH}_{3} \mathrm{O}_{4} \mathrm{CH}_{3}$, and therefore the overall $\mathrm{CH}_{3} \mathrm{OO}+\mathrm{CH}_{3} \mathrm{OO}$ reaction, is hence likely to be very fast - in agreement with experimental results finding rapid overall self-reaction rates in the gas phase for most nontertiary $\mathrm{RO}_{2} .{ }^{13}$ We note that the activation barrier predicted for $\mathrm{CH}_{3} \mathrm{CH}_{2} \mathrm{O}_{4} \mathrm{CH}_{2} \mathrm{CH}_{3}$ decomposition at the $\operatorname{CCSD}(\mathrm{T}) / \mathrm{cc}-\mathrm{pVDZ}$ level by Lee et al. is above $10.0 \mathrm{kcal} / \mathrm{mol} .{ }^{17}$ The computational demands of the XMC-QDPT2 $(10,8)$ transition state optimizations prevent us from evaluating activation barriers for larger $\mathrm{RO}_{2}+\mathrm{R}^{\prime} \mathrm{O}_{2}$ systems, but as the key interactions between the four oxygen atoms are similar, they are unlikely to be dramatically higher than in the $\mathrm{CH}_{3} \mathrm{OO}$ $+\mathrm{CH}_{3} \mathrm{OO}$ case, at least for most primary and secondary $\mathrm{RO}_{2}$. The barriers to $\mathrm{RO}_{4} \mathrm{R}^{\prime}$ decomposition are thus unlikely to hinder ROOR' dimer formation in the atmosphere - the yield and formation rate of ROOR' will instead be controlled by a competition between the three channels illustrated in Figure 1. We note that while the XMC-QDPT2 barrier height predictions are far from quantitative, single-point energy calculations using the much more accurate and 
expensive MRCISD method (see section S2 of the SI) also indicate that the barriers for formation and decomposition of $\mathrm{CH}_{3} \mathrm{O}_{4} \mathrm{CH}_{3}$ lie far below the reactants.

The low barrier predicted for the decomposition of the $\mathrm{CH}_{3} \mathrm{O}_{4} \mathrm{CH}_{4}$ tetroxide is seemingly in contrast with experimental electron spin resonance (ESR) studies ${ }^{26,27}$ indicating possible stabilization of $\left(\mathrm{CH}_{3}\right)_{3} \mathrm{CO}_{4} \mathrm{C}\left(\mathrm{CH}_{3}\right)_{3}$ and other tetroxides formed from tertiary $\mathrm{RO}_{2}$ at temperatures below $-115{ }^{\circ} \mathrm{C}$. However, test calculations on the $\left(\mathrm{CH}_{3}\right)_{3} \mathrm{COO}+\left(\mathrm{CH}_{3}\right)_{3} \mathrm{COO}$ reaction at the CASSCF(10,8)/6-311++G(d,p) level, using the same active space as for the $\mathrm{CH}_{3} \mathrm{OO}+\mathrm{CH}_{3} \mathrm{OO}$ reaction (see section $\mathrm{S} 3$ and $\mathrm{S} 8$ of the SI) indicates that the stabilized species observed in these experiments is not actually the covalently bound $\mathrm{RO}_{4} \mathrm{R}^{\prime}$ tetroxide, but the $\mathrm{RO}_{2} \ldots \mathrm{R}^{\prime} \mathrm{O}_{2}$ complex. For $\mathrm{R}=\left(\mathrm{CH}_{3}\right)_{3} \mathrm{C}$, and presumably also for larger tertiary $\mathrm{R}$, the barrier for the conversion of the complex into the tetroxide is substantial, as indicated by both the experimental ESR findings, ${ }^{26,27}$ the low overall self-reaction rates of tertiary $\mathrm{RO}_{2},{ }^{13}$ and our CASSCF data. As suggested by Lee et al. ${ }^{17}$ this is likely due to the absence of stabilising $\mathrm{CH} . . \mathrm{O}$ interactions in the formation of tertiary $\mathrm{RO}_{4} \mathrm{R}^{\prime}$. However, the subsequent decomposition of the tetroxide is extremely rapid, and actual covalently bound tetroxides are thus extremely unlikely to be experimentally detectable even for tertiary $\mathrm{RO}_{2}$.

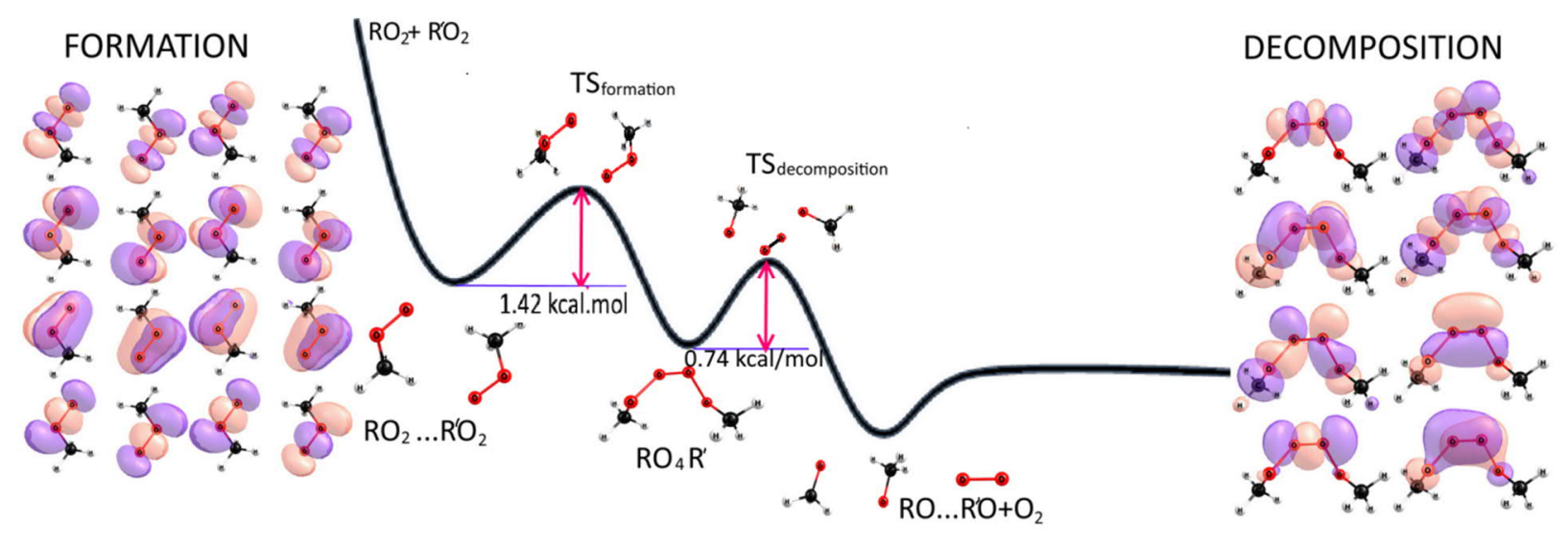


Fig. 2. Schematic XMC-QDPT2 $(10,8) / 6-311++G(d, p)$ potential energy surface for the formation and decomposition of $\mathrm{CH}_{3} \mathrm{O}_{4} \mathrm{CH}_{3}$, together with the calculated activation barrier heights. The molecular orbitals of the active spaces used in describing the transition states for $\mathrm{CH}_{3} \mathrm{O}_{4} \mathrm{CH}_{3}$ formation (left) and decomposition (right) are also shown.

\section{CONFORMATIONAL SAMPLING, ISC RATE CALCULATIONS AND SELECTION OF SYSTEMS}

The ${ }^{3} \mathrm{O}_{2}$ molecule is only weakly bound to the $\mathrm{RO} \ldots \mathrm{O}_{2} \ldots \mathrm{R}$ 'O cluster formed by the mechanism discussed above, and in the gas phase likely evaporates (dissociates) promptly from the cluster. Our subsequent calculations are thus performed for the ${ }^{3}(\mathrm{RO} \ldots \mathrm{R}$ 'O) complexes remaining after the loss of ${ }^{3} \mathrm{O}_{2}$. For the systematic ISC rate constant $\left(k_{I S C}\right)$ calculations, we selected the following ${ }^{3}\left(\mathrm{RO} \ldots \mathrm{R}^{\prime} \mathrm{O}\right) \quad$ clusters: $\quad{ }^{3}\left(\mathrm{CH}_{3} \mathrm{O}^{\bullet} \ldots \mathrm{CH}_{3} \mathrm{O}^{\bullet}\right)$, ${ }^{3}\left(\mathrm{CH}_{3}(\mathrm{CO}) \mathrm{CH}_{2} \mathrm{O}^{\bullet} \ldots \mathrm{CH}_{3}(\mathrm{CO}) \mathrm{CH}_{2} \mathrm{O}^{\bullet}\right), \quad{ }^{3}\left(\mathrm{CH}_{3}(\mathrm{CO}) \mathrm{CH}_{2} \mathrm{O}^{\bullet} \ldots \mathrm{HOCH}_{2} \mathrm{CH}\left(\mathrm{O}^{\bullet}\right) \mathrm{CH}_{2} \mathrm{CH}_{3}\right) \quad$ and ${ }^{3}\left(\mathrm{HOCH}_{2} \mathrm{CH}\left(\mathrm{O}^{\bullet}\right) \mathrm{CH}_{2} \mathrm{CH}_{3} \ldots \mathrm{HOCH}_{2} \mathrm{CH}\left(\mathrm{O}^{\bullet}\right) \mathrm{CH}_{2} \mathrm{CH}_{3}\right)$. ROOR' corresponding to the latter three systems were all detected in the experiments of Berndt et. al. ${ }^{11}$ All of the clusters except ${ }^{3}\left(\mathrm{CH}_{3} \mathrm{O}^{\bullet} \ldots \mathrm{CH}_{3} \mathrm{O}^{\bullet}\right)$ possess multiple different conformers, which were sampled systematically.

A systematic exploration of the potential energy surface (PES) of a polyatomic system, especially a polymolecular system, using quantum chemical methods is computationally very expensive. In this study, we apply a "building up" configurational sampling approach to search for low-energy configurations for ${ }^{3}\left(\mathrm{RO} \ldots \mathrm{R}^{\prime} \mathrm{O}\right)$ clusters. Clusters with different binding patterns were built from a relatively small set of different alkoxy radical monomers (RO), considering multiple conformations for each monomer. Different pre-optimizations and filtering processes were used in search of energetically low-lying structures for minimal computational cost. 


\subsection{CONFORMATIONAL SAMPLING OF MONOMERS (ISOLATED ALKOXY}

\section{RADICALS)}

Systematic conformer searches of the "monomer" RO were carried out using Spartan $16{ }^{28}$ In the searches, every nonterminal bond is rotated a certain number of times, and an optimization is performed using the Merck molecular force field (MMFF) to determine if the resulting structure represents a distinct minimum on the PES. The default number of rotations in Spartan (also used in this study) is 3 for bonds between $\mathrm{sp}^{3}$ hybridized atoms and 2 for bonds between $\mathrm{sp}^{2}$ hybridized atoms. The atom type of the radical oxygen was manually set to generic divalent $\mathrm{O}$ (type 6) to avoid Spartan treating the system as an anion. Conformer distributions for each RO monomer were then generated using MMFF, in order to produce a representative set of unique conformers.

\subsection{CONFIGURATIONAL SAMPLING OF TRIPLET DIMER CLUSTERS OF TWO} ALKOXY RADICALS

A systematic configurational sampling of cluster structures was carried out using a "building up" approach. ${ }^{29}$ The possible RO monomer conformers from the previous step were optimized at the $\omega \mathrm{b} 97 \mathrm{X}-\mathrm{D} / \mathrm{aug}-\mathrm{cc}-\mathrm{pVTZ}$ level of theory, and the Natural Bond Orbital (NBO) population analysis ${ }^{30}$ was performed for each structure. This yielded partial charges for each atom. These charges were then utilized by the ABCluster program, ${ }^{31,32}$ which uses the Artificial Bee Colony $(\mathrm{ABC})$ algorithm,${ }^{33}$ for the configurational sampling of the RO...R'O dimer clusters on the triplet PES. Clusters formed from all combinations of conformers of the different studied monomers were considered, and 300 cluster configurations were generated for each combination. The interaction between monomers was treated by Coulomb interactions (using the calculated 
NBO partial charges) and Lennard-Jones parameters taken from the CHARMM force field database. ${ }^{34,35}$ The monomer structures were kept rigid during the sampling process to minimize the search effort: only the orientation and position of the rigid monomers was optimized to minimize the total interaction energy.

The total number of structures created by ABCluster is too large to be treated at a high level of theory. In order to exclude irrelevant and duplicate structures, thereby minimizing the computational cost, single point (SP) electronic energies were calculated using the semiempirical GNF-xTB level of theory. ${ }^{36}$

Identical structures were removed if their geometries were similar, i.e. the difference in the radius of gyration, $\Delta \mathrm{Rg}$, and electronic energy, $\Delta \mathrm{E}$, were less than $0.01 \AA$, and 0.001 hartree, respectively. (The radius of gyration is explained in detail in the following section.) After this, 100 structures (for each $\mathrm{RO}+\mathrm{R}$ 'O combination) were uniformly sampled, and selected for further DFT calculations (see Figure 3 for an illustration of the uniform sampling).

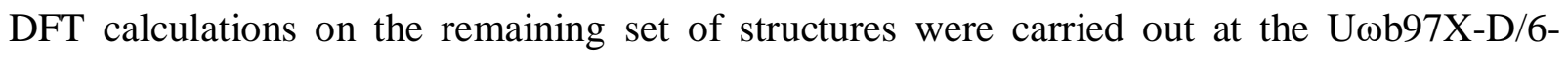
$31+\mathrm{G}^{*}$ and Uwb97X-D/aug-cc-pVTZ levels of theory ${ }^{37,38}$ using Gaussian 16, revision B.01. ${ }^{39}$ At the lower $\left(\mathrm{U} \omega \mathrm{b} 97 \mathrm{X}-\mathrm{D} / 6-31+\mathrm{G}^{*}\right)$ level, only geometry optimization was performed (without frequency calculations) using loose optimization criteria (keyword: Opt=Loose). Conformers with relative energy higher than $5 \mathrm{kcal} / \mathrm{mol}$ (compared to the lowest-energy U $\omega \mathrm{b} 97 \mathrm{X}-\mathrm{D} / 6$ -

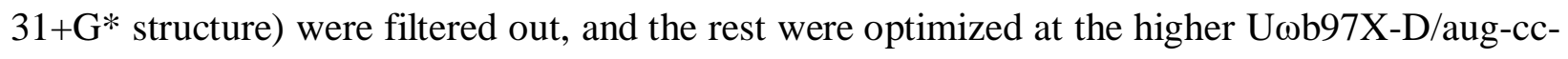
pVTZ level, including a frequency calculations (keywords: Opt=verytight Int=ultrafine Freq). Conformers with near identical dipole moments and relative energies after optimization at the

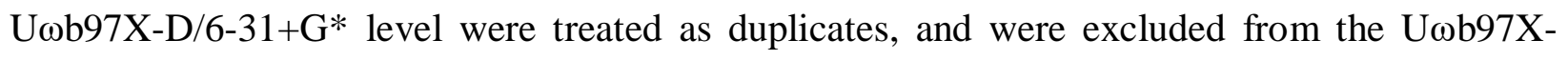
D/aug-cc-pVTZ level optimization. 


\subsection{UNIQUENESS AND FILTERING}

In a few steps of our "building up" configurational sampling protocol, redundant structures were excluded, and various cut-offs were applied, to reduce computational cost. For each cluster, we computed a collective coordinate, called the radius of gyration $\mathrm{Rg}$, which is defined as:

$$
R_{g}^{2}=\frac{\sum_{i=1}^{N} m_{i}\left|\vec{r}_{-}-\vec{r}_{C O M}\right|^{2}}{\sum_{i=1}^{N} m_{i}},
$$

where $m_{i}$ is the mass of atom $i, \vec{r}_{l}$ is its position, $\vec{r}_{\text {com }}$ represents the center of mass of the whole cluster, and $N$ is the total number of atoms,. Other collective co-ordinates used here are the electronic energy and the dipole moment. ${ }^{40,41}$ Two molecules are considered as different if all collective coordinates differ within a threshold. For example, if two molecules have similar radius of gyration $(\mathrm{Rg})$ and energy $(\mathrm{E})$, then the molecules are same. We used thresholds of 0.01 $\AA$ for Rg and 0.001 Hartree for energy.

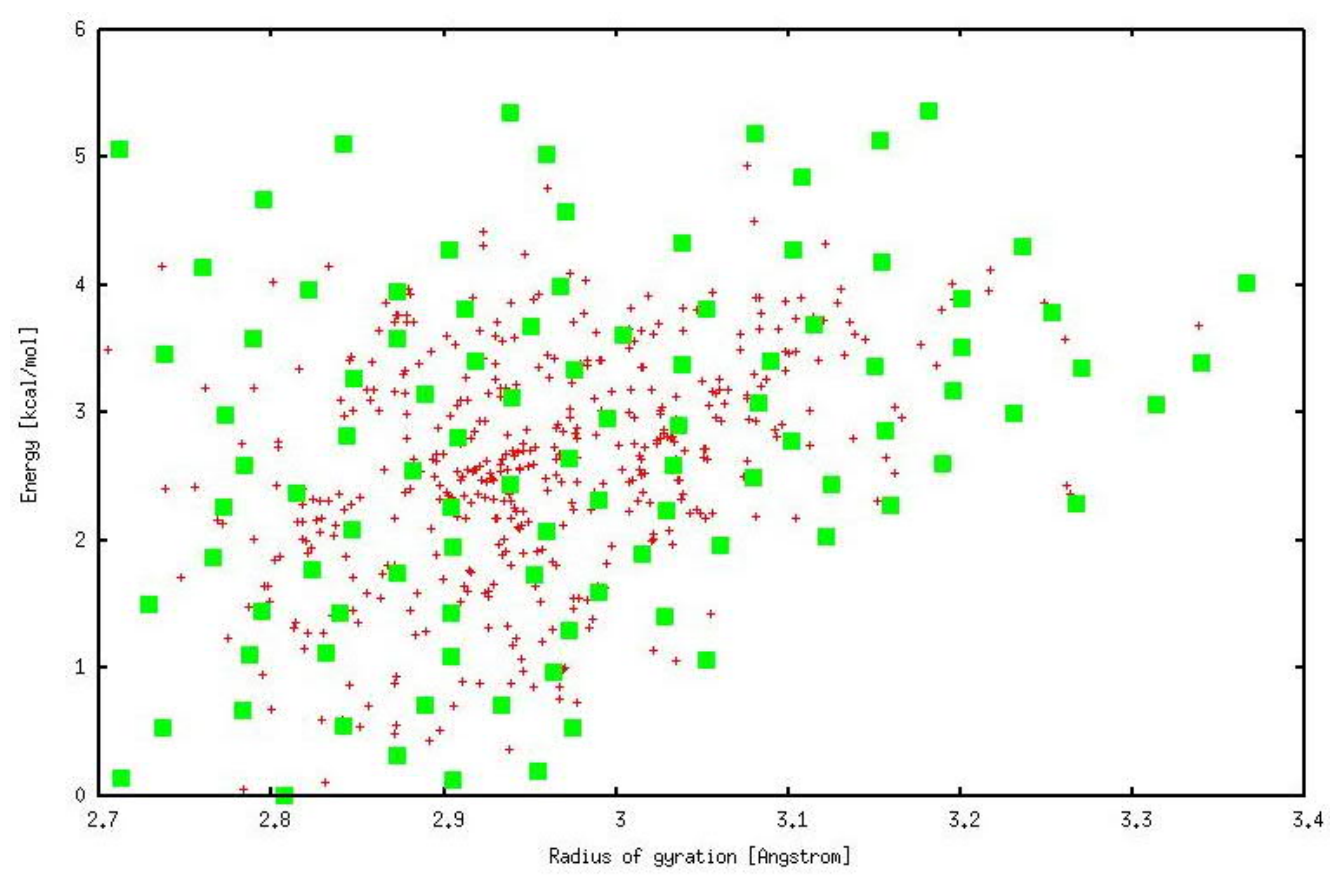


Fig. 3: This figure illustrates how the uniform selection of conformations is applied to a large set of structures. The relative single point GNF-xTB energies of several hundreds of cluster structures (produced by the ABCluster program) are plotted with respect to their radius of gyration (red crosses). The green points show the 100 structures selected for further calculations.

Figure 3 illustrates a uniform sampling of structures from large set of configurations. In this specific case $\left({ }^{3}(R, R-\mathrm{Bu}(\mathrm{OH}) \mathrm{O} \ldots \mathrm{Bu}(\mathrm{OH}) \mathrm{O})\right)$, the GNF-xTB single-point energy of clusters (with structures obtained from the ABCluster program) is plotted with respect to their $\mathrm{Rg}$. We then uniformly select a specified amount of structures (in this case 100) from full set. This method does not guarantee that the global minima will be found. However, if the selected points are not too far from each other, then very low-lying structures (close to the global minima) will be found by the approach, and thus the obtained lowest-energy structure will be good approximation of the true global minimum. As the purpose of the present sampling is not to exhaustively explore all possible ${ }^{3}\left(\mathrm{RO} \ldots \mathrm{R}^{\prime} \mathrm{O}\right)$ structures, but to obtain a representative set for evaluating the variation of ISC rates, the approach used here is more than sufficient.

\subsection{ISC CALCULATIONS}

For each system, we then picked the lowest-energy conformer (the global minimum), as well as two other representative low-energy conformers with substantially different bonding patterns, in order to assess how the ISC rates vary between different conformers. As the $\mathrm{HOCH}_{2} \mathrm{CH}\left(\mathrm{O}^{\bullet}\right) \mathrm{CH}_{2} \mathrm{CH}_{3}$ alkoxy radical contains a stereocenter, the ${ }^{3}\left(\mathrm{HOCH}_{2} \mathrm{CH}\left(\mathrm{O}^{\bullet}\right) \mathrm{CH}_{2} \mathrm{CH}_{3} \ldots \mathrm{HOCH}_{2} \mathrm{CH}\left(\mathrm{O}^{\bullet}\right) \mathrm{CH}_{2} \mathrm{CH}_{3}\right)$ dimer possesses two different diastereomer pairs (stereoisomers which are not mirror images of each other) which may have 
different reactivities. For this study, we picked the $R, R$ and $R, S$ stereoisomers. In addition, we performed proof-of-concept calculations on arbitrary conformers of two larger systems, ${ }^{3}\left(\mathrm{CH}_{3}(\mathrm{CO}) \mathrm{CH}_{2} \mathrm{O}^{\bullet} \ldots \mathrm{C}_{9} \mathrm{H}_{13} \mathrm{O}_{6}\right)$ and ${ }^{3}\left(\mathrm{C}_{9} \mathrm{H}_{13} \mathrm{O}_{6} \ldots \mathrm{C}_{9} \mathrm{H}_{13} \mathrm{O}_{6}\right)$, where $\mathrm{C}_{9} \mathrm{H}_{13} \mathrm{O}_{6}$ is a peroxyradical formed in the $\mathrm{OH}$ oxidation of 1,3,5-trimethylbenzene as reported by Berndt et al. ${ }^{11}$ In the following text, we use the shorthand notation of ${ }^{\mathbf{3}}(\mathbf{M e O})_{2},{ }^{3}(\mathbf{A c O})_{2},{ }^{3}(\mathbf{A c O} . . . H O B u O)$, ${ }^{3}(\mathrm{HOBuO})_{2, \mathrm{RR}},{ }^{3}(\mathrm{HOBuO})_{2, \mathrm{RS}},{ }^{3}\left(\mathrm{AcO} \ldots \mathrm{C}_{9} \mathrm{H}_{13} \mathrm{O}_{6}\right)$ and ${ }^{3}\left(\mathrm{C}_{9} \mathrm{H}_{13} \mathrm{O}_{6} \ldots \mathrm{C}_{9} \mathrm{H}_{13} \mathrm{O}_{6}\right)$ for the seven systems investigated. See section S6 for figures of the clusters.

For the ${ }^{3}(\mathbf{M e O})_{2}$ cluster, the XMC-QDPT2 $(10,8) / 6-311++G(d, p)$ method was used in the geometry optimization of the triplet ground state. For the systematically sampled ${ }^{\mathbf{3}}(\mathbf{A c O})_{2}$, ${ }^{3}(\mathrm{AcO} \ldots \mathrm{HOBuO}),{ }^{\mathbf{3}}(\mathrm{HOBuO})_{2, \mathrm{RR}}$ and ${ }^{\mathbf{3}}(\mathrm{HOBuO})_{2, \mathrm{RS}}$, systems, the final geometries were optimized using the $\omega \mathrm{B} 97 \mathrm{xd}$ density functional and the aug-cc-pVTZ basis set, as described in the supporting information. The larger ${ }^{3}\left(\mathbf{A c O} . . . \mathrm{C}_{9} \mathrm{H}_{13} \mathrm{O}_{6}\right)$ and ${ }^{3}\left(\mathrm{C}_{9} \mathrm{H}_{13} \mathrm{O}_{6} \ldots \mathrm{C}_{9} \mathrm{H}_{13} \mathrm{O}_{6}\right)$ systems were optimized at the $\omega \mathrm{B} 97 \mathrm{xd} / 6-311++\mathrm{G}(\mathrm{d}, \mathrm{p})$ level as optimizations with the larger basis set were prohibitively expensive. All density functional theory calculations were carried out using the Gaussian 16 program. ${ }^{39}$. The Cartesian coordinates for all systems are given in section S7 of the SI.

The ISC rate constant $k_{I S C}$ was calculated using the method describing in Ref. ${ }^{22}$ The general formula for the calculation of radiationless rate constants $\left(k_{\mathrm{nr}}\right)$ according to this method is:

$$
k_{\mathrm{nr}}=\sum_{n}\left|V_{i 0, f n}\right|^{2} \Gamma_{f n}\left[\Delta_{i f}^{2}+\frac{\Gamma_{f n}^{2}}{4}\right]^{-1}
$$


where $i$ is the initial electronic state, $f$ is the final electronic state, $n$ is a vibrational level of $f, \Gamma_{f n}$ is the relaxation width of the vibronic level $\left|f n>, \Delta_{i f}=\right| E_{i 0}-E_{f n} \mid$ is the resonance defect energy between the initial and final vibronic states, and $V_{i 0, f n}$ is the matrix element of the perturbation operator. Only the lowest vibronic state is considered for the initial state at room temperature. In the case of ISC, the perturbation operator is the spin-orbit coupling interaction. Eq. (2) written in atomic units holds at ambient temperatures $(\mathrm{T} \leq 300 \mathrm{~K})$ when $k_{\mathrm{nr}}<<\Gamma_{f n} . \Gamma_{f n}$ is about $10^{14} \mathrm{~s}^{-1}$, and is generally much larger than $k_{n r}$ which typically has values around $10^{7}-10^{12} \mathrm{~s}^{-1}{ }^{22}$ The $\Delta_{i f}$ value is not larger than $100 \mathrm{~cm}^{-1}$ for polyatomic molecules. ${ }^{22}$ The expression can be simplified to Eq. (3) when assuming that $\Gamma_{f n}$ depends only weakly on the vibrational level $n$, and that $\Delta_{i f}<<\Gamma_{f n}: 22$

$$
k_{\mathrm{nr}}=1.6 \cdot 10^{9} \sum_{n}\left|V_{i 0, f n}\right|^{2}(3) .
$$

where $k_{n r}$ in $\mathrm{s}^{-1}$.

In the case of ISC the formula (3) becomes

$$
k_{I S C}=1.6 \cdot 10^{9}<i\left|\hat{H}_{S O}\right| f>^{2}\left(\sum_{n_{1}, n_{2} \ldots, n_{3 N-6}}^{E_{E_{i f}}=n_{1} \omega_{1}+n_{2} \omega_{2}+.+n_{3 N-6} \omega_{3 N-6}} \prod_{k=1}^{3 N-6} \sqrt{\frac{\exp \left(-y_{k}\right) y_{k}^{n_{k}}}{n_{k} !}}\right)^{2}
$$

where $y_{k}$ is the Huang-Rhys factor of the $i: t h$ mode and $\omega_{k}$ is the frequency of the $k: t h$ mode. $<i\left|H_{S O}\right| f>\left(\right.$ in $\left.\mathrm{cm}^{-1}\right)$ is the matrix element of the spin-orbital coupling interaction operator $H_{S O}$ between the initial and final electronic states $i$ and $f$. $E_{\text {if }}$ is the energy gap between the electronic states.

The Huang-Rhys factors were calculated according to Eq (5):

$$
y_{j}=\frac{1}{2} \omega_{j} \Delta Q_{j}^{2}(5),
$$


where $\Delta Q_{j}^{2}$ is the equilibrium position displacement of the $j: t h$ mode. We note that for all studied ${ }^{3}\left(\mathrm{RO} \ldots \mathrm{R}^{\prime} \mathrm{O}\right)$ systems, almost all modes with wavenumbers between 10 and $1000 \mathrm{~cm}^{-1}$ have $y>0.01$ and are thus promotive modes. Additionally, each system has one mode with a wavenumber around $\sim 1400 \mathrm{~cm}^{-1}$ which has $0.1<y<0.5$. This mode corresponds mainly to the vibration of $\mathrm{C}-\mathrm{O}$ bonds. The existence of a large number of low-frequency and at least one high frequency promotive modes leads to a large contribution in the summation of FC factors in Eq. (4).

As the ground state of the studied clusters is a triplet, we note that the process considered here is in principle a thermally activated ISC, as it occurs from the ground $\mathrm{T}_{1}$ state to $\mathrm{S}_{1}$ or to higher singlet states. The intersystem crossing rate constant $\left(k_{I S C}\right)$ can be calculated using the formula ${ }^{42}$ :

$$
k_{I S C}=k_{I S C} \cdot \exp \left(-E_{i f} / k T\right)(6)
$$

where $k$ is Boltzmann's factor and $E_{\text {if }}$ is energy gap between the electronic states.

In order to calculate $k_{I S C}$, the following parameters are thus needed: $E_{i f},\left\langle i\left|H_{S O}\right| f\right\rangle$, $\omega_{j}$ and $\Delta Q_{j}$. Multireference methods are required for this task, as we deal with open-shell systems. ${ }^{19,24}$ The energies of triplet and singlet states were calculated using XMC-QDPT2/6$311++G(d, p)$ on Firefly. ${ }^{20,21}$ We used the equilibrium geometries of the triplet ground states $\mathrm{T}_{1}$ for the all clusters. The active space included six electrons in four molecular orbitals (MOs). They were initially generated at the HF/6-311++G(d,p) level of theory as canonical orbitals, and are similar to the antibonding $\pi^{*}$-MOs of the carbon monoxide molecule, except with an even larger contribution from the atomic p-orbitals of the $\mathrm{O}$ atoms (see Figure 4 for an illustration). We also tested using larger active spaces (more than 4 MOs and 6 electrons), but in all tested cases only the first four MOs actually contribute to the $\mathrm{T}_{1}-\mathrm{T}_{4}$ and $\mathrm{S}_{1}-\mathrm{S}_{4}$ states, strongly 
suggesting that the CASSCF $(6,4)$ active space is sufficient. State averaging was performed for the first four triplet $\left(T_{1}-T_{4}\right)$ and the first four singlet $\left(S_{1}-S_{4}\right)$ states. We note that the $T_{1}-T_{4}$ and $S_{1}-$ $\mathrm{S}_{4}$ are all within $8000 \mathrm{~cm}^{-1}$ of each other, and are effectively spin-mixed for all the systems considered. The higher states $\left(\mathrm{S}_{5}, \mathrm{~T}_{5}\right.$ and higher) are located above $\sim 20000 \mathrm{~cm}^{-1}$ and cannot be included into the state-averaging procedure.

The matrix elements of spin-orbital coupling interaction (SOCME) between $T_{1}-T_{4}$ and $S_{1}-S_{4}$ were computed at CASSCF level of theory, but with the XMC-QDPT2/6-311++G(d,p) energies as the zero-order energies within the perturbation theory. ${ }^{22}$ GAMESS-US ${ }^{43}$ was used for this calculation.

The $\Delta Q_{j}$ and $\omega_{j}$ were calculated at the CASSCF level of theory for all clusters using the hessian of the initial $\mathrm{T}_{1}$ state and the gradient of the final state. ${ }^{22}$
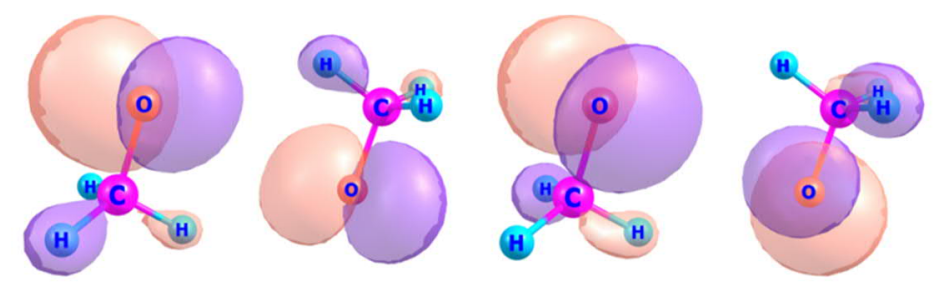

$$
\text { 1) } \pi_{\mathrm{x}}-\pi_{\mathrm{x}}
$$

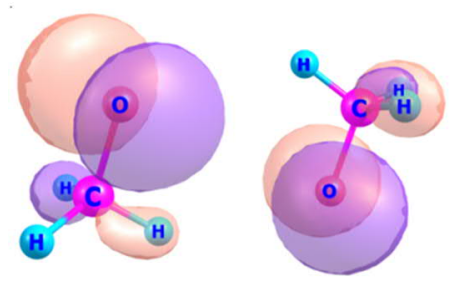

3) $\pi_{x}-\pi_{y}$

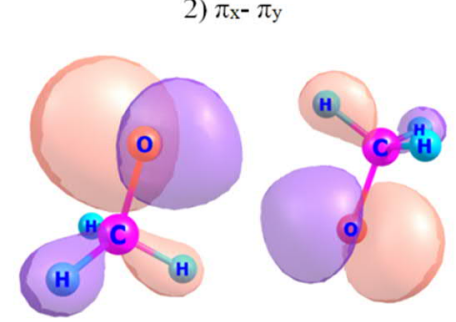

4) $\pi_{x}-\pi_{x}$

Fig. 4. State-averaged CASSCF $(6,4) / 6-311++G(d, p)$ molecular orbitals for the ${ }^{3}(\mathbf{M e O})_{2}$ cluster.

ISC rate constant for ${ }^{3}\left(\mathrm{RO} . . . \mathrm{R}^{\prime} \mathrm{O}\right)$ system 
The calculated results for all systems are summarized in Figure 5, and presented in Section S5 of the SI. Detailed results for the ${ }^{\mathbf{3}}(\mathbf{M e O})_{2}$ case are also shown in Figure 6 and Table 1. As seen from Table 1, the SOCME for ${ }^{\mathbf{3}}(\mathbf{M e O})_{2}$ is small for the $T_{1} \rightarrow S_{1}$ process, and large for the $\mathrm{T}_{1} \rightarrow \mathrm{S}_{2}$ and $\mathrm{T}_{1} \rightarrow \mathrm{S}_{3}$ processes. The total value of $k_{R I S C}$ from $\mathrm{T}_{1}$ to the lowest four singlet states is around $10^{13} \mathrm{~s}^{-1}$, making the ISC process from $\mathrm{T}_{1}$ to the lowest singlet states extremely fast. The internal conversion (IC) process from $S_{2}, S_{3}$ and $S_{4}$ to $S_{1}$ states very likely occurs with rate constants $\left(k_{I C}\right)$ on the order of $10^{14} \mathrm{~s}^{-1}$, as the energy gaps between these states are small $\left(<10000 \mathrm{~cm}^{-1}\right)^{22}$. Thus the full spin-flip process between the $T_{1}$ and $S_{1}$ state has a rate constant of about $10^{13} \mathrm{~s}^{-1}$. This is surprisingly high, given that $\mathrm{CH}_{3} \mathrm{OOCH}_{3}$ formation has not been unambiguously documented, even as a minor channel, for the $\mathrm{CH}_{3} \mathrm{OO}+\mathrm{CH}_{3} \mathrm{OO}$ reaction ${ }^{13}$. This may be related to the small size of the system - energy non-accommodation could lead to fragmentation of the nascent $\mathrm{CH}_{3} \mathrm{OOCH}_{3}$ before it can be detected. 


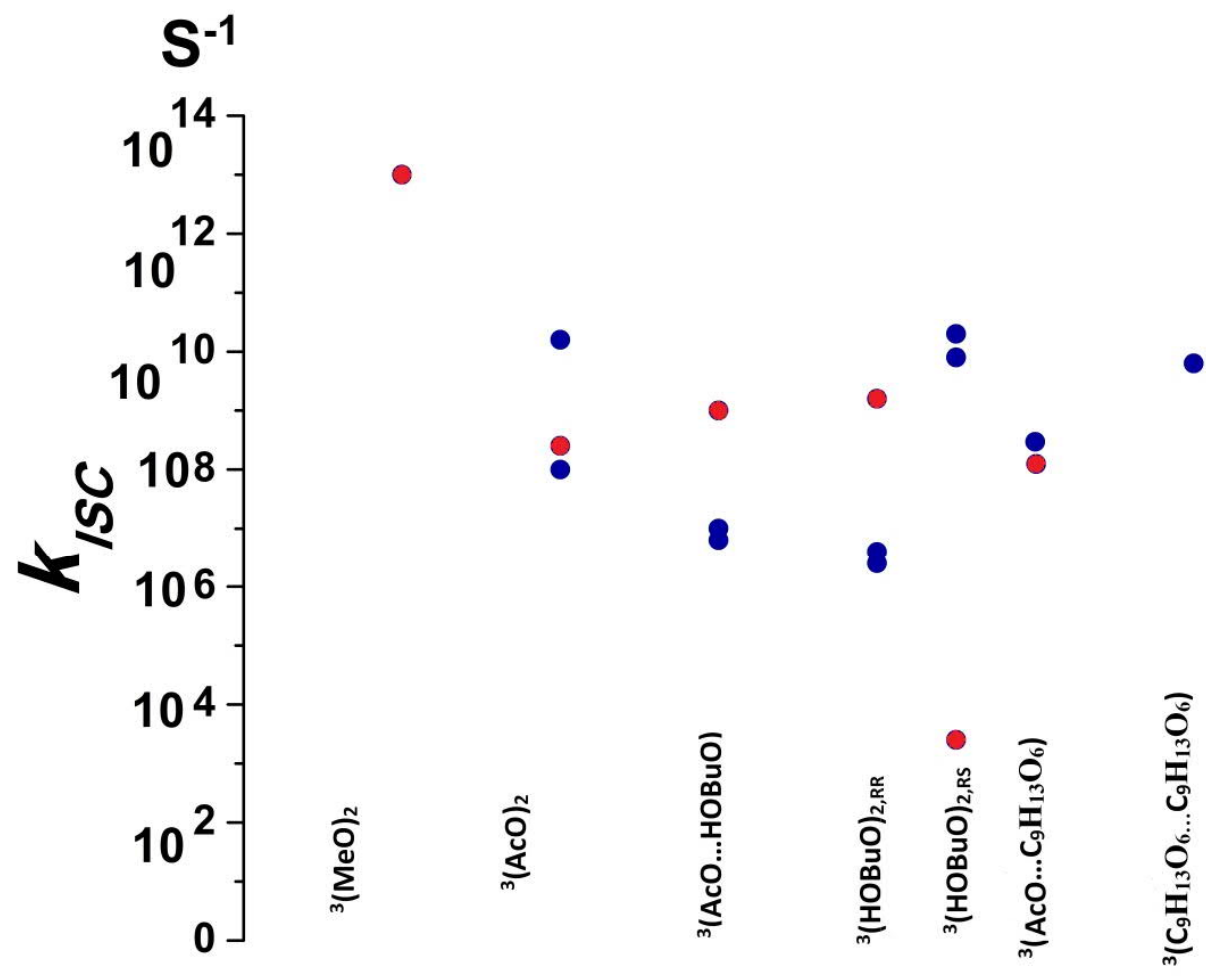

Fig. 5. The computed $\mathrm{k}_{\mathrm{ISC}}$ rates for different ${ }^{3}(\mathrm{RO} \ldots \mathrm{R}$ 'O) complexes. Each point corresponds to a different conformer, with the lowest-energy conformer indicated in red.

According to Table $1, k_{I S C}\left(\mathrm{~T}_{1} \rightarrow \mathrm{S}_{2}\right)$ and $k_{I S C}\left(\mathrm{~T}_{1} \rightarrow \mathrm{S}_{3}\right)$ are significantly larger than $k_{I S C}$ $\left(\mathrm{T}_{1} \rightarrow \mathrm{S}_{1}\right)$ and $k_{I S C}\left(\mathrm{~T}_{1} \rightarrow \mathrm{S}_{4}\right)$, mainly due to the larger SOCME values. This can be understood by considering the state-averaged MOs shown in Figure 4, which mostly correspond to p-type atomic orbitals of the oxygen atom. The spin-orbital coupling interaction operator $\left(\hat{H}_{S O}\right)$ is proportional to $\hat{L} \cdot \hat{S}$, where $\hat{L}$ is the angular momentum and $\hat{S}$ is the spin operator. ${ }^{43}$ The action of $\hat{L}$ mainly influences the angular part of the wavefunction of p-type orbitals, as the radial parts of these orbitals are almost indentical. ${ }^{44}$ Therefore, $\hat{L}$ acts to convert the $\left(\pi_{\mathrm{x}}-\pi_{\mathrm{y}}\right)-\mathrm{MO}$ shown in Figure 4 into a $\left(\pi_{\mathrm{x}}-\pi_{\mathrm{x}}\right)-\mathrm{MO}$, and vice versa. The weights of the contributions of each 
MO in the $T_{1}, S_{1}$ and $S_{4}$ states are almost identical, with $\left(\pi_{x}-\pi_{x}\right)$-MOs dominating. In contrast, the $S_{2}$ and $S_{3}$ states are dominated by $\left(\pi_{\mathrm{x}}-\pi_{\mathrm{y}}\right)$-MOs. Therefore, after rotation of the MOs by the $\hat{L}$ operator, the overlap between for example the $\left(\pi_{\mathrm{x}}-\pi_{\mathrm{y}}\right)$-MO of $\psi\left(S_{1}\right)$ and the $\left(\pi_{\mathrm{x}}-\pi_{\mathrm{x}}\right)$-MO of $\psi\left(T_{1}\right)$ is small, leading to a small value also for $\left\langle\psi\left(S_{1}\right)\left|\hat{H}_{S O}\right| \psi\left(T_{1}\right)\right\rangle$. In contrast, after rotation the overlap between the MOs of $\psi\left(S_{2}\right)$ or $\psi\left(S_{3}\right)$ and $\psi\left(T_{1}\right)$ are large, leading to large values for $<\psi\left(S_{2}\right)\left|\hat{H}_{S O}\right| \psi\left(T_{1}\right)>$ and $<\psi\left(S_{3}\right)\left|\hat{H}_{S O}\right| \psi\left(T_{1}\right)>$. This is the reason for the large SOCMEs and $k_{I S C}$ between the $\mathrm{T}_{1}$ and $\mathrm{S}_{2}$, and $\mathrm{T}_{1}$ and $\mathrm{S}_{3}$, electronic states. A similar trend is found also for almost all of the other ${ }^{3}\left(\mathrm{RO} \ldots \mathrm{R}^{\prime} \mathrm{O}\right)$ systems, as shown in Section S5.

Table 1. The SOCME $\left(\mathrm{cm}^{-1}\right)$, energy gap $\left(\mathrm{cm}^{-1}\right)$ and $k_{I S C}\left(\mathrm{~s}^{-1}\right)$ computed for the ${ }^{\mathbf{3}}(\mathbf{M e O})_{2}$ cluster.

\begin{tabular}{llll}
\hline Transition & SOCME & Energy gap & $k_{I S C}$ \\
\hline $\mathrm{T}_{1} \rightarrow \mathrm{S}_{1}$ & 0.30 & 25.0 & $k_{I S C}\left(\mathrm{~T}_{1} \rightarrow \mathrm{S}_{1}\right)=9 \cdot 10^{8} \mathrm{~s}^{-1}$ \\
\hline $\mathrm{T}_{1} \rightarrow \mathrm{S}_{2}$ & 135 & 430.0 & $k_{I S C}\left(\mathrm{~T}_{1} \rightarrow \mathrm{S}_{2}\right)=1 \cdot 10^{13} \mathrm{~s}^{-1}$ \\
\hline $\mathrm{T}_{1} \rightarrow \mathrm{S}_{3}$ & 57.0 & 505.0 & $k_{I S C}\left(\mathrm{~T}_{1} \rightarrow \mathrm{S}_{3}\right)=9 \cdot 10^{12} s^{-1}$ \\
\hline $\mathrm{T}_{1} \rightarrow \mathrm{S}_{4}$ & 2.0 & 1000.0 & $k_{I S C}\left(\mathrm{~T}_{1} \rightarrow \mathrm{S}_{4}\right)=1 \cdot 10^{6} s^{-1}$ \\
\end{tabular}




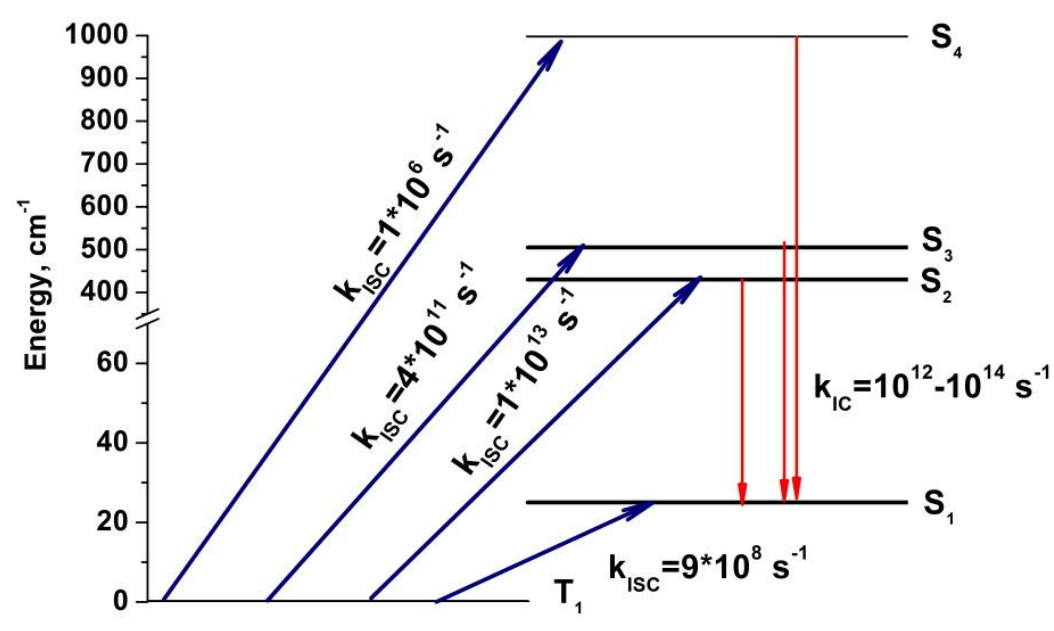

Fig. 6. Jablonski diagram showing the $T_{1}$ ground state, the first four excited singlet states $S_{1} \ldots S_{4}$, and corresponding computed intersystem crossing rates $\left(k_{I S C}\right)$ and estimated internal conversion rates $\left(k_{I C}\right)$ for the ${ }^{3}(\mathbf{M e O})_{2}$ cluster.

Figure 5 illustrates two important features of the ISC process of ${ }^{3}\left(\mathrm{RO} \ldots \mathrm{R}^{\prime} \mathrm{O}\right)$ dimers. First, the overall $k_{I S C}$ rate varies significantly between both different RO species, and between different conformers of the same RO species. This large variation is due to both the very large range of values obtained for the SOCMEs, especially for the $T_{1} \rightarrow S_{1}$ transition, as well as the variation in the energy gaps between the $\mathrm{T}_{1}$ and $\mathrm{S}_{2}$ or $\mathrm{S}_{3}$ states. As for ${ }^{3}(\mathbf{M e O})_{2}$, the $k_{I S C}$ for the $\mathrm{T}_{1} \rightarrow \mathrm{S}_{4}$ transition is always low due to the large energy gap. For each system, at least one conformer can always be found with an ISC rate above $10^{8} \mathrm{~s}^{-1}$, and the rates for the lowestenergy conformers found in our sampling are also all above $10^{7} \mathrm{~s}^{-1}$, except for the $R, S$ enantiomer of ${ }^{\mathbf{3}}(\mathbf{H O B u O})_{2}$ which has an anomalously low rate of $4 \cdot 10^{3} \mathrm{~s}^{-1}$. However, the ${ }^{\mathbf{3}}(\mathbf{H O B u O})_{2, \mathbf{R S}}$ system also has a conformer less than $2 \mathrm{kcal} / \mathrm{mol}$ higher in energy with an ISC rate of $3 \cdot 10^{10} \mathrm{~s}^{-1}$. Due to the relatively loose binding between the two RO moieties, it is very likely that the different conformers rapidly interconvert at atmospheric temperatures. An ISC is thus feasible 
provided that at least one conformer with a sufficiently high ISC rate exists - which is the case for all systems studied here. Overall, our results are thus fully consistent with those of Berndt et $\mathrm{al}^{11}$, who measure efficient ROOR' formation in all six of the larger systems investigated here. The relative ISC rates for the lowest-energy conformers are also in line with the experimental result that dimer formation from the $\mathrm{CH}_{3}(\mathrm{CO}) \mathrm{CH}_{2} \mathrm{OO}{ }^{\bullet}+\mathrm{HOCH}_{2} \mathrm{CH}\left(\mathrm{OO}^{\bullet}\right) \mathrm{CH}_{2} \mathrm{CH}_{3}$ cross reaction is faster than from the $\mathrm{CH}_{3}(\mathrm{CO}) \mathrm{CH}_{2} \mathrm{OO}^{\bullet}+\mathrm{CH}_{3}(\mathrm{CO}) \mathrm{CH}_{2} \mathrm{OO}$ self-reaction. The very large difference between the two ${ }^{3}\left(\mathrm{RO} \ldots \mathrm{R}^{\prime} \mathrm{O}\right)$ diastereomers relevant to the $\mathrm{HOCH}_{2} \mathrm{CH}\left(\mathrm{OO}^{\bullet}\right) \mathrm{CH}_{2} \mathrm{CH}_{3}$ self-reaction prevent a quantitative comparison to this system, as the stereoselectivity of the reaction sequence forming the original tetroxides is unknown. However, we note that the overall dimer yield will depend not only on the absolute ISC rate, but also on the three-way competition between ISC, fragmentation to RO...R'O, and intermolecular RO H-shift to $\mathrm{R}_{-\mathrm{H}}=\mathrm{O}+\mathrm{ROH}$. Not only the ISC, but also the two other rates will likely vary between different chemical systems. All three are also likely to be very rapid, as the RO...R'O binding is relatively weak, and $\mathrm{RO} \mathrm{H}$-abstractions are generally fast. The key structural and dynamic features determining the ultimate yields of the three channels remain an open question.

A third feature revealed by Figure 3 is that the ISC rates of the two computed ${ }^{3}(\mathbf{H O B u O})$ diastereomers differ by about 7 orders of magnitude for the lowest-energy conformers, despite the two conformers having very similar H-bonding patterns (see sections S5 and S7 of the SI). This difference is due to the SOCME value for the $\mathrm{T}_{1} \rightarrow \mathrm{S}_{1}$ transition, which has a moderate value of $1.85 \mathrm{~cm}^{-1}$ for the lowest-energy conformer of the $R, R$ enantiomer, leading to a large ISC rate as the energy gap is small, but is zero for the lowest-energy conformer of the $R, S$ enantiomer. Even unimolecular peroxy radical reactions are well-known to be stereoselective, so qualitatively it is not surprising that there are even stronger stereochemical effects in bimolecular $\mathrm{RO}_{2}+\mathrm{R}^{\prime} \mathrm{O}_{2}$ 
reactions. ${ }^{45}$ However, as evident from Figure 5, the difference between the two diastereomers of the same system accounts for the majority of the overall variation in computed ISC rates. Since virtually all peroxyradicals relevant to secondary organic aerosol formation in the atmosphere (including for example those generated in the oxidation of isoprene or monoterpenes) possess at least one stereocenter, this strong stereoselectivity creates an additional challenge for quantitatively modelling dimer yields.

\section{Conclusion}

Intersystem crossings have been proposed as a possible route for ROOR' dimer formation already in $2003^{18}$, and the detailed mechanism of $\mathrm{RO}_{2}+\mathrm{R}^{\prime} \mathrm{O}_{2}$ reactions, including the mechanism for ROOR' formation, has been identified as a major open question in atmospheric chemistry in $2008^{46}$. Despite this, actual ISC rates for peroxyradical self- and cross-reaction systems have never been computed before. Using the multireference quantum chemical method XMC-QDPT2, we have first demonstrated that the transition states for the $\mathrm{CH}_{3} \mathrm{O}_{2}+\mathrm{CH}_{3} \mathrm{O}_{2}$ reaction lie far below the energy of the free reactants, implying that the barriers are "submerged", and the reaction consequently quite fast. Despite substantial error sources in our XMC-QDPT2 calculations, originating mainly from the limited treatment of dynamic correlation due to computational constraints, our extensive benchmarking demonstrates that this qualitative conclusion likely holds regardless of the precise computational model used. Other primary and secondary $\mathrm{RO}_{2}$ could also be expected to behave similarly, while tertiary $\mathrm{RO}_{2}$ (based on test calculations on the $\left(\mathrm{CH}_{3}\right)_{3} \mathrm{CO}_{2}+\left(\mathrm{CH}_{3}\right)_{3} \mathrm{CO}_{2}$ reaction) are likely to have appreciably higher barriers for the formation, though not the decomposition, of $\mathrm{RO}_{4} \mathrm{R}^{\prime}$ tetroxide intermediates. Next, we have shown that ISC rates for ${ }^{3}\left(\mathrm{RO}^{\bullet} \ldots \mathrm{R}^{\prime} \mathrm{O}^{\bullet}\right)$ complexes formed in $\mathrm{RO}_{2}+\mathrm{R}^{\prime} \mathrm{O}_{2}$ reactions are 
very high; typically on the order of $10^{6}-10^{13} \mathrm{~s}^{-1}$, and also vary strongly between different conformers of the same chemical system, and especially between diastereomers. All in all, our results demonstrate that gas-phase $\mathrm{ROOR}^{\prime}$ dimer formation via ${ }^{3}\left(\mathrm{RO}^{\bullet} \ldots \mathrm{R}^{\prime} \mathrm{O}^{\bullet}\right)$ clusters and subsequent ISCs is a competitive, and probably important, process in the atmosphere.

\section{ASSOCIATED CONTENT}

Supporting information file (pdf): Multireference character diagnostics, method benchmarking, calculations on the $\left(\mathrm{CH}_{3}\right)_{3} \mathrm{COO}+\left(\mathrm{CH}_{3}\right)_{3} \mathrm{COO}$ reaction, energies for the first excited singlet states of the minima and transition states for the formation and decomposition of $\mathrm{CH}_{3} \mathrm{O}_{4} \mathrm{CH}_{3}$, the

SOCME $\left(\mathrm{cm}^{-1}\right)$, Energy gap $\left(\mathrm{cm}^{-1}\right)$ and $\mathrm{k}_{\mathrm{ISC}}\left(\mathrm{s}^{-1}\right)$ for all studied ${ }^{3}\left(\mathrm{RO} \ldots \mathrm{R}^{\prime} \mathrm{O}\right)$ systems, Cartesian coordinates.

\section{ACKNOWLEDGMENT}

We thank the Academy of Finland - 1315600 and Svenska Kulturfonden - 136102 for funding, and the CSC IT Center for Science in Espoo, Finland, for computing time.

\section{REFERENCES}

1. Silva, R. A.; West, J.; Zhang Y.; Anenberg, S.; Lamarque J.-F.; Shindell D. T.; Collins W. J., Dalsoren, S.; Faluvegi, G.; Folberth, G. Global premature mortality due to anthropogenic outdoor air pollution and the contribution of past climate change. Environ. Res. Lett. 2013, 8, 034005.

2. Brauer, M; Freedman, G.; Frostad, J.; van Donkelaar, A.; Martin, R. V.; Dentener, F.; van Dingenen, R.; Estep, K.; Amini, H.; Apte, J. S.; Balakrishnan, K.; Barregardh, L.; Broday, D.; Feigin, V.; Ghosh, S.; Hopke, P. K.; Knibbs, L. D.; Kokubo, Y.; Liu, Y.; Ma, S.; Morawska, L.; 
Texcalac Sangrador, J. S.; Shaddickr, G.; Anderson, H. R.; Vos, T.; Forouzanfar, M. H.; Burnett, R. T.; Cohen, A. Ambient Air Pollution Exposure Estimation for the Global Burden of Disease 2013. Environ. Sci. Technol. 2016, 50, 79-88.

3.Seinfeld, J.H.; Bretherton, C.; Carslaw, K. S.; Coe, H.; DeMott, P. J.; Dunlea, E. J.; Feingold, G.; Ghan, S.; Guenther, A. B.; Kahn, R.; Kraucunas, I.; Kreidenweis, S. M.; Molina, M. J.; Nenes, A.; Penner, J. E.; Prather, K. A.; Ramanathan, V.; Ramaswamy, V.; Rasch, P.J.; Ravishankara, A. R.; Rosenfeld, D.; Stephens, G.; Wood, R. Improving our fundamental understanding of the role of aerosol-cloud interactions in the climate system, PNAS 2016, 113, $5781-5790$

4. Ehn, M.; Thornton, J. A.; Kleist, E.; Sipilä, M.; Junninen, H.; Pullinen, I.; Springer, M.; Rubach, F.; Tillmann, R.; Lee, B.; Lopez-Hilfiker, F.; Andres, S.; Acir, I. H.; Rissanen, M.; Jokinen, T.; Schobesberger, S.; Kangasluoma, J.; Kontkanen, J.; Nieminen, T.; Kurtén, T.; Nielsen, L. B.; Jørgensen, S.; Kjaergaard, H. G.; Canagaratna, M.; Maso, M. D., Berndt, T.; Petäjä, T.; Wahner, A.; Kerminen, V. M.; Kulmala, M.; Worsnop, D. R.; Wildt, J., Mentel, T. F. A large source of low- volatility secondary organic aerosol. Nature 2014, 506, 476-479.

5. Tröstl, J.; Chuang, W. K.; Gordon, H.; Heinritzi, M.; Yan, C.; Molteni, U.; Ahlm, L.; Frege, C.; Bianchi, F.; Wagner, R.; Simon, M.; Lehtipalo, K.; Williamson, C.; Craven, J. S.; Duplissy, J.; Adamov, A.; Almeida, J.; Bernhammer, A. K.; Breitenlechner, M.; Brilke, S.; Dias, A.; Ehrhart, S.; Flagan, R. C.; Franchin, A.; Fuchs, C.; Guida, R.; Gysel, M.; Hansel, A.; Hoyle, C. R.; Jokinen, T.; Junninen, H.; Kangasluoma, J.; Keskinen, H.; Kim, J.; Krapf, M.; Kürten, A.; Laaksonen, A.; Lawler, M.; Leiminger, M.; Mathot, S.; Möhler, O.; Nieminen, T; Onnela, A. Petäjä, T.; Piel, F. M.; Miettinen, P.; Rissanen, M. P.; Rondo, L., Sarnela, N.; Schobesberger, S.; Sengupta, K.; Sipilä, M.; Smith J. N.; Steiner, G.; Tomè, A.; Virtanen, A.; Wagner, A. C.; 
Weingartner, E.; Wimmer, D.; Winkler, P. M.; Ye, P.; Carslaw, K. S.; Curtius, J.; Dommen, J.; Kirkby J.; Kulmala, M.; Riipinen, I.; Worsnop, D. R.; Donahue, N. M.; Baltensperger, U. The role of low-volatility organic compounds in initial particle growth in the atmosphere, Nature 2016, 533, 527-531.

6. Mohr. M.; Lopez-Hilfiker, F.D.; Yli-Juuti, T.; Heitto, A.; Lutz, A.; Hallquist, M.; D'Ambro E. L.; Rissanen M. P.; Hao L.; Schobesberger, S.; Kulmala, M.; Mauldin, R. L., Makkonen, U.; Sipilä, M.; Petäjä, T.; Thornton. Ambient observations of dimers from terpene oxidation in the gas phase: Implications for new particle formation and growth. J. A. Geophys. Res. Lett. 2017, 44, 2598-2966.

7. Zhao, Y.; Thornton, J. A.; Pyem H. O. T. Quantitative constraints on autoxidation and dimer formation from direct probing of monoterpene-derived peroxy radical chemistry. PNAS 2018, $115,12142-12147$.

8. Bianchi, F.; Kurtén, T.; Riva, M.; Mohr, C.; Rissanen, M. P.; Roldin, P.; Berndt, T.; Crounse, J. D.; Wennberg, P. O.; Mentelo, T. F.; Wildto, J.; Junninen, H.; Jokinen, T.; Kulmala, M.; Worsnop, D. R.; Thornton, J. A.; Donahue, N.; Kjaergaard, H. G.; Ehn, M. Highly oxygenated organic molecules (HOM) from gas-phase autoxidation involving peroxy radicals: A key contributor to atmospheric aerosol. Chem. Rev. 2019, 10.1021/acs.chemrev.8b0039.

9. Ehn, M.; Berndt, T.; Wildt, J.; Mentel, T. Highly Oxygenated Molecules from Atmospheric Autoxidation of Hydrocarbons: A Prominent Challenge for Chemical Kinetics Studies: Highly oxygenated molecules from atmospheric autoxidation of hydrocarbons. Int. J. Chem. Kinet. 2017, 49, 821-831.

10. Kalberer, M.; Paulsen, D.; Sax, M.; Steinbacher, M.; Dommen, J.; Prevot, A. S. H.; Fisseha, R.; Weingartner, E.; Frankevich, V.; Zenobi, R.; Baltensperger, U. Identification of 
Polymers as Major Components of Atmospheric Organic Aerosols. Science 2004, 303, 16591662.

11. Berndt, T.; Scholz, W.; Mentler, B.; Fischer, L.; Herrmann, H.; Kulmala, M.; Hansel, Accretion Product Formation from Self- and Cross-Reactions of RO2 Radicals in the Atmosphere. A. Angew. Chem. Int. Ed. 2018, 57, 3820-3824.

12. Noell, A.C.; Alconcel, L.S.; Robichaud, D. J.; Okumura, M.; Sander, S. P. Near-infrared kinetic spectroscopy of the $\mathrm{HO} 2$ and $\mathrm{C} 2 \mathrm{H} 5 \mathrm{O} 2$ self-reactions and cross reactions. J. Phys. Chem. A 2010, 114, 6983-6995.

13. Orlando, J. J.; Tyndall, G. S. Laboratory studies of organic peroxy radical chemistry: an overview with emphasis on recent issues of atmospheric significance. Chem. Soc. Rev. 2012, 41, 6294-6317.

14. Zhang, P.; Wang, W.; Zhang, T.; Chen, L.; Du, Y.; Li, C.; Lü, L. Theoretical study on the mechanism and kinetics for the self-Reaction of C2H5O2 radicals. J. Phys. Chem. A 2012, 116, 4610-4620.

15. Liang, Y-N.; Li, J.; Wang, Q.-D.; Wang, F.; Li, X-Y. Computational Study of the Reaction Mechanism of the Methylperoxy Self-Reaction. J. Phys. Chem. A 2011, 115, 13534-13541.

16. Russell, G. A. Deuterium-isotope effects in the autoxidation of aralkyl hydrocarbons. Mechanism of the interaction of peroxy radicals. J. Am. Chem. Soc. 1957, 79, 3871-3877.

17. Lee, R.; Gryn'ova, G.; Ingold, K. U.; Coote, M. L. Why are sec-alkylperoxyl bimolecular self-reactions orders of magnitude faster than the analogous reactions of tert-alkylperoxyls? The unanticipated role of $\mathrm{CH}$ hydrogen bond donation. Phys. Chem Chem. Phys. 2016, 18, 2367323679. 
18. Ghigo, G.; Maranzana, A.; Tonachini, G. Combustion and atmospheric oxidation of hydrocarbons: Theoretical study of the methyl peroxyl self-reaction. J. Chem. Phys. 2003, 118, 10575-10583.

19. Vereecken, L.; Glowacki, D. R.; Pilling, M. J. Theoretical Chemical Kinetics in Tropospheric Chemistry: Methodologies and Applications. Chem. Rev. 2015, 115, 4063-4114.

20. Granovsky, A. A. Extended multi-configuration quasi-degenerate perturbation theory: the new approach to multi-state multi-reference perturbation theory. J. Chem. Phys. 2011, 134, 214113.

21. Granovsky, A. A. Firefly version 8.0.0,http://classic.chem.msu.su/gran/firefly/index.html.

22. Valiev, R. R.; Cherepanov, V. N.; Baryshnikov, G. V.; Sundholm, D. First-principles method for calculating the rate constants of internal-conversion and intersystem-crossing transitions, 2018, Phys. Chem. Chem. Phys. 20, 6121-6133.

23. Minaev B. F., Valiev, R. R.; Nikonova, E. N.; Gadirov, R. M.; Solodova, T. A.; Kopylova, T. N. Kopylova. Computational and Experimental Investigation of the Optical Properties of the Chromene Dye. J. Phys. Chem. A, 2015, 119, 1948-1956.

24. Valiev, R. R.; Fliegl, H.; Sundholm, D. Bicycloaromaticity and Baird-type bicycloaromaticity of dithienothiophene-bridged [34]octaphyrins. Phys. Chem. Chem. Phys. 2018, 20, 17705-17713.

25. Valiev, R. R.; Fliegl, H.; Sundholm, D. Closed-shell paramagnetic porphyrinoids. Chem. Commun. 2017, 53, 9866-9869.

26.Bennet, E.; Brown, D. M.; Mile, B., The Equilibrium between Tertiary Alkylperoxyradicals and Tetroxide Molecules, Chemical Communications, 1969, 376, 504-505. 
27.Adamic, K.; Howard, J. A.; Ingold, K. U; Di-t-alkyl Tetroxides, Chemical Communications, 1969, 377, 505-506.

28. Spartan 16; Wavefunction Inc.: Irvine, C. A., 2016

29. Jensen, F. Introduction to Computational Chemistry. John Wiley \& Sons, Inc., USA, 2006.

30. Glendening, E. D., Reed, A. E., Carpenter, J. E., and Weinhold, F. Nbo version 3.1.

31. Zhang, J., and Dolg, M. Global optimization of rigid molecular clusters by the articial bee colony algorithm. Phys. Chem. Chem. Phys. 2016, 18, 3003-3010.

32. Zhang, J., and Dolg, M. ABCluster: the artifcial bee colony algorithm for cluster global optimization. Chem. Phys. 2015, 17, 24173-24181.

33. Karaboga, D., and Basturk, B. On the performance of artificial bee colony (ABC) algorithm. Appl. Soft Comput. 2008, 8, 687- 697.

34. Yu, W., He, X., Vanommeslaeghe, K., and Jr., A. D. M. Extension of the charmm general force field to sulfonyl-containing compounds and its utility in bimolecular simulations. J. Comput. Chem. 2012, 33, 2451-2468.

35. Vanommeslaeghe, K., Hatcher, E., Acharya, C., Kundu, S., Zhong, S., Shim, J., Darian, E., Guvench, O., Lopes, P.,Vorobyov, I., and Jr., A. D. M. Charmm general force field: A force field for drug-like molecules compatible with the charmm all-atom additive biological force fields. J. Comput. Chem. 2010, 31, 671-690.

36. Grimme, S., Bannwarth, C., and Shuskov, P. A robust and accurate tight-binding quantum chemical method for structures, vibrational frequencies, and noncovalent interactions of large molecular systems parametrized for all spd-block elements $(\mathrm{z}=1-86)$. J. Chem. Theory Comput. 2017, 13, 1989-2009. 
37. Chai J.-D.; Head-Gordon. M. Systematic optimization of long-range corrected hybrid density functionals. J. Chem. Phys., 2008, 128, 084106.

38. Hehre, W. J.; Ditchfield, R.; Pople, J. A. Self-Consistent Molecular Orbital Methods. XII. Further Extensions of Gaussian Type Basis Sets for Use in Molecular Orbital Studies of Organic Molecules. J. Chem. Phys. 1972, 56, 2257-2261.

39. Gaussian 16, Revision B.01, Fisch, M. J.; Trucks, G. W.; Schlegel, H. B.; Scuseria, G. E.; Robb, M. A.; Cheeseman, J. R.; Scalmani, G.; Barone, V.; Petersson, G. A.; Nakatsuji, H.; Li, X.; Caricato, M.; Marenich, A. V.; Bloino, J.; Janesko, B. G.; Gomperts, R.; Mennucci, B.; Hratchian, H. P.; Ortiz, J. V.; Izmaylov, A. F.; Sonnenberg, J. L.; Williams-Young, D.; Ding, F.; Lipparini, F.; Egidi, F.; Goings, J.; Peng, B.; Petrone, A.; Henderson, T.; Ranasinghe, D.; Zakrzewski, V. G.; Gao, J.; Rega, N.; Zheng, G.; Liang, W.; Hada, M.; Ehara, M.; Toyota, K.; Fukuda, R.; Hasegawa, J.; Ishida, M.; Nakajima, T.; Honda, Y.; Kitao, O.; Nakai, H.; Vreven, T.; Throssell, K.; Montgomery, J. A., Jr.; Peralta, J. E.; Ogliaro, F.; Bearpark, M. J.; Heyd, J. J.; Brothers, E. N.; Kudin, K. N.; Staroverov, V. N.; Keith, T. A.; Kobayashi, R.; Normand, J.; Raghavachari, K.; Rendell, A. P.; Burant, J. C.; Iyengar, S. S.; Tomasi, J.; Cossi, M.; Millam, J. M.; Klene, M.; Adamo, C.; Cammi, R.; Ochterski, J. W.; Martin, R. L.; Morokuma, K.; Farkas, O.; Foresman, J. B.; Fox, D. J. Gaussian, Inc., Wallingford CT, 2016.

40. Hotteling, H. Relations between two sets of variates. Biometrika 1936, 28, 321-377.

41. Pearson, K. On lines and planes of closest to systems of points in space. Philos. Mag. 1901, $6,559-572$.

42. Gadirov, R. M.; Valiev, R. R.; Samsonova, L. G.; Degtyarenko, K. M.; Izmailova, N. V.; Odod, A. V.; Krasnikova, S. S.; Yakushchenko, I. K.; Kopylova, T. N. Thermally activated 
delayed fluorescence in dibenzothiophene sulfone derivatives: Theory and experiment. Chem. Phys. Lett. 2019, 717, 53-58.

43. Schmidt, M. W.; Baldridge, K. K.; Boatz, J. A.; Elbert, S. T.; Gordon, M. S.; Jensen, J. H.; Koseki, S.; Matsunaga, N.; Nguyen, K. A.; Su, S.; Windus, T. L. General atomic and molecular electronic structure system. J. Comput. Chem. 1993, 14, 1347-1363.

44. Minaev, B.; Baryshnikov, G.; Agren, H., Principles of phosphorescent organic light emitting devices. Phys. Chem. Chem. Phys. 2014, 16,1 719-1758.

45. Wennberg, P. O.; Bates, K. H.; Crounse, J. D.; Dodson, L. D.; McVay, R. C.; Mertens, L. A.; Nguyen, T. B.; Praske, E.; Schwantes, R. H.; Smarte, M. D.; Clair, J. M. St.; Teng, A. P.; Zhang, H.; Seinfeld, J. H. Gas-Phase Reactions of Isoprene and Its Major Oxidation Products. Chem. Rev. 2018, 118, 3337-3390.

46. Dibble, D. Failures and limitations of quantum chemistry for two key problems in the atmospheric chemistry of peroxy radicals, Atmos. Environ. 2008, 42, 5837-5848. 